\title{
Alterations of lymphocyte subsets in children of diabetic mothers
}

\author{
U. Roll, J. Scheeser, E.Standl, A.-G. Ziegler \\ Diabetes Research Institute and Third Medical Department, City Hospital Schwabing, Munich, Germany
}

Summary To investigate the impact of diabetic mothers on the maturation of the immune system in their offspring, immunophenotypic markers of major lymphocyte subpopulations were evaluated by twocolour flow cytometric analysis in 160 healthy children of diabetic mothers (100 with insulin-dependent diabetes mellitus (IDDM); 48 with gestational diabetes), including 22 neonates, 45 infants aged 812 months, 46 children aged 1-2 years, 29 children aged 3-6 years and 18 children aged $7-17$ years. Results were compared with 21 neonates of healthy mothers from our hospital and with 110 paediatric subjects of a reference population. In neonates of diabetic mothers, percentages of total lymphocytes $(p=0.044)$, T and B lymphocytes $(p=0.004$, respectively) were significantly decreased compared to our neonates of healthy mothers. By subdividing the group of neonates in offspring of mothers with IDDM $(n=15)$ or gestational diabetes $(n=7)$, differences compared to normal neonates were mainly observed in neonates of mothers with IDDM (T lymphocytes: $p=0.006$; B lymphocytes: $p=0.008)$. In cord blood, $45.5 \%$ of neonates had antibodies to islet cells, insulin or glutamic acid decarboxylase, most likely transmitted through the placenta of the diabetic mother. No association was found between altera- tions of lymphocyte subsets and antibody-positivity in cord blood, nor was there any correlation of lymphocyte counts and mean $\mathrm{HbA}_{1}$ during pregnancy, maternal age at delivery, diabetes duration, or neonatal birth weight, respectively. Comparisons among age groups from newborn infants through adolescents revealed higher percentages of total lymphocytes and lower percentages of activated $T$ cells in children of diabetic mothers compared to children of the reference population between the age of 1 to 6 years (67$73 \%$ of the cases above and $62-77 \%$ below the interquartiles of the reference range, respectively). No significant differences in lymphocyte subpopulations between children of mothers with IDDM diabetes and gestational diabetes have been detected. In addition, there were no abnormalities of lymphocyte subsets in children who are at high risk for the development of IDDM. In summary, we suggest that the observed changes in children of diabetic mothers may reflect a cellular immune reaction to the particular maternal environment, characterized by both an abnormal metabolic state and persisting autoimmunity in the affected mother. [Diabetologia (1994) 37: 1132-1141]

Key words Lymphocyte subsets, insulin-dependent diabetes mellitus, gestational diabetes, cord blood.
Received: 23 February 1994

and in revised form: 16 June 1994

Corresponding author: U.Roll, Diabetes Research Institute, Koelner Platz 1, D-80804, Munich, Germany

Abbreviations: ICA, Islet cell antibodies; IAA, insulin autoantibodies; GAD-ab, antibodies to glutamic acid decarboxylase; IDDM, insulin-dependent diabetes mellitus; FITC, fluorescein isothiocyanate; $\mathrm{PE}$, phycoerythrin.
Accumulating evidence suggests that insulin-dependent diabetes mellitus (IDDM) is an autoimmune disease which is both genetically determined and externally stimulated by environmental factors [1]. Very little is known about the influence of an autoimmune disease in the mother on the maturation of the immune system in the fetus. Based on studies about the risk of IDDM developing in the offspring of a parent with IDDM, Warram and co-workers [2] 
Table 1. Antibodies and reagents used for antigen identification of lymphocyte subsets

\begin{tabular}{|c|c|c|}
\hline Antibody; fluorochrome & Antigen & Cellular distribution \\
\hline Anti-Leu 4; FITC & CD3 $\left(\operatorname{Leu} 4^{+} 12^{-}\right)$ & T lymphocytes \\
\hline Anti-Leu $12 ; \mathrm{PE}$ & CD19 (Leu $\left.4^{-} 12^{+}\right)$ & B lymphocytes \\
\hline Anti-Leu 2; PE & CD8 (Leu $\left.3^{-} 2^{+}\right)$ & T suppressor/cytotoxic \\
\hline Anti-Leu 4; FITC & $\mathrm{CD} 3 ; \mathrm{CD}_{16}^{+}$and/or CD56 ${ }^{+}$ & natural killer cells \\
\hline Anti-Leu $11+$ Anti-Leu 19; PE & $\left(\right.$ Leu $4^{-/ 11}{ }^{+}$and $\left.19^{+}\right)$ & \\
\hline
\end{tabular}

have described a lower risk of IDDM in children of mothers with IDDM than of fathers with IDDM, and similar findings have been reported by investigators in Germany [3]. Although the underlying factor responsible for that lower risk remains unknown, it has been suggested that the exposure to maternal diabetes in utero protects offspring from diabetes during the first two decades of life [4]. This is supported by the observation that children born before the onset of diabetes in the mother have a higher risk of developing the disease than children exposed in utero to her diabetes and born in the first or second pregnancy after the onset of maternal diabetes [5].

In a prospective study from birth, we have previously shown that islet cell antibodies (ICA) and insulin autoantibodies (IAA) are common in cord blood of neonates of mothers with IDDM suggesting that they are transplacentally acquired, but they normally disappear after birth. A few offspring, however, developed autoantibodies to insulin or islet cells as first markers of humoral immune reactions at 9 months or 2 years of age [6]. It has been suggested that the cellular immune system participates in the autoimmune destruction of pancreatic beta cells [7], but controversial data have been published on the phenotyping of lymphocyte subsets in new-onset and long-term diabetic subjects [8-14]. In contrast to studies about humoral autoimmune markers in prediabetic subjects, data about cellular changes in firstdegree relatives or in offspring of diabetic mothers are scarce $[10,11,15,16]$.

To investigate age-related changes of lymphocyte populations in children of diabetic mothers in correlation with humoral immune markers and clinical variables, five different age groups of paediatric subjects were recruited and characterized for lymphocyte subsets and antibodies to pancreatic islets, and compared to normal neonates and to an infant reference population [17].

\section{Subjects and methods}

The study population consisted of 160 healthy children of diabetic mothers, including 22 neonates, 45 infants aged 8 to 12 months, 46 children aged 1 to 2 years, 29 children aged 3 to 6 years and 18 children aged 7 to 17 years. All diabetic moth- ers attended the outpatient unit of the Third Medical Department of the City-Hospital Schwabing during pregnancy every 4 weeks and were hospitalized at the obstetric department of our hospital at delivery. Blood samples for determination of lymphocyte subsets and sera for measurement of autoantibodies to islet cells (ICA), glutamic acid decarboxylase (GAD-ab) and insulin (IAA), respectively, were obtained from all children, with parental consent. All children were healthy at the time of blood drawing and had no episodes of recent infections or other diseases in the past. Of all children studied, 100 were born to mothers with IDDM, 48 to mothers with gestational diabetes and 12 to healthy mothers who later developed either IDDM or gestational diabetes $(n=6$, respectively). Of all mothers with gestational diabetes (50\% White classification type $\mathrm{A}, 50 \%$ White classification type $\mathrm{Bg}$ ), $47.8 \%$ had a body mass index less than $25.5 \mathrm{~kg} / \mathrm{m}^{2}$, and $29.5 \%$ were $\mathrm{ICA}^{+}$and/or $\mathrm{IAA}^{+}$positive. Altogether, $67.4 \%$ had either normal weight and/or were antibody-positive. At delivery, the maternal age of all diabetic mothers ranged from 19 to 45 years (mean \pm SD: IDDM: $29.0 \pm 4.0$ years; gestational diabetes: $32.4 \pm 4.6$ years), diabetes duration from 1 to 27 years (mean $\pm \mathrm{SD}$ : IDDM: $13.1 \pm 6.9$ years), the mean $\mathrm{HbA}_{1}$ during pregnancy from 5.3 to $9.4 \%$ (mean $\pm \mathrm{SD}$ : IDDM $6.8 \pm 1.4 \%$; gestational diabetes $7.1 \pm 0.8 \%$; normal range $<8.0 \%$ ). The gestation duration was 36 to 42 weeks (mean \pm SD: IDDM $39.2 \pm 1.3$ weeks; gestational diabetes $38.9 \pm 1.5$ weeks) and the neonatal birth weight 2005 to $5100 \mathrm{~g}$ (mean $\pm \mathrm{SD}$ : IDDM $3433 \pm 586 \mathrm{~g}$; gestational diabetes $3464 \pm 726 \mathrm{~g})$.

Results were compared with 21 neonates of healthy mothers from our hospital (mean maternal age \pm SD: $24.4 \pm 5.4$ years; range $17-33$ years; mean gestation duration $\pm \mathrm{SD}$ : $40.0 \pm 1.3$ weeks; mean birth weight $\pm \mathrm{SD}$ : $3271 \pm 1044 \mathrm{~g}$ ) and with 110 paediatric subjects of a reference population from the literature. The children in this population were derived from the UK and Belgium and were attending the hospital for minor trauma or surgical procedures (age 0 to 17 years; divided into four different age groups: birth, 111 months, 1-6 years and 7-17 years, respectively [17]). All normal newborn infants were delivered at term with normal weight for age and had no evidence of infection or congenital abnormalities.

Sample preparation and FACS-analysis. A minimum of $1 \mathrm{ml}$ fresh cord or peripheral venous blood was collected into tubes containing ethylenediaminetetra-acetic acid and stored at room temperature for no longer than $6 \mathrm{~h}$ before staining. A complete blood cell count, including an automated differential count was performed with a microcellcounter $\mathrm{CC}-170$ (Sysmex Diagnostica AG, Hamburg, Germany). Immunophenotyping of lymphocytes was performed by a lysed wholeblood method using matched combinations of murine monoclonal antibodies directly conjugated to fluorescein isothiocyanate (FITC) or phycoerythrin (PE) as shown in Table 1. 
Table 2. Lymphocyte subsets (\%; median, 25. and 75. percentile) in cord blood of children of normal and diabetic mothers with either IDDM or GDM and with either positive or negative cord blood antibody titres (AB + neonates with at least one detectable antibody of ICA, IAA, or GAD; $\mathrm{AB}$ - antibody negative neonates)

\begin{tabular}{|c|c|c|c|c|c|c|c|c|c|}
\hline $\begin{array}{l}\text { Cell population } \\
\text { percentage }(\%) \\
\text { median }(p 25-75)\end{array}$ & $\begin{array}{l}\text { Normal } \\
\text { offspring } \\
n=21\end{array}$ & $p$ & $\begin{array}{l}\text { Total DM } \\
\text { offspring } \\
n=22\end{array}$ & $p$ & $\begin{array}{l}\text { IDDM } \\
\text { offspring } \\
n=15\end{array}$ & $p$ & $\begin{array}{l}\text { GDM } \\
\text { offspring } \\
n=7\end{array}$ & $\begin{array}{l}\mathrm{Ab}^{+} \mathrm{DM} \\
\text { offspring } \\
n=9\end{array}$ & $\begin{array}{l}\mathrm{Ab}-\mathrm{DM} \\
\text { offspring } \\
n=13\end{array}$ \\
\hline Total lymphocytes & $30(27-33)$ & 0.044 & $27(22-30)$ & & $27(24-32)$ & & $22(17-29)$ & $27(24-38)$ & $25(19-32)$ \\
\hline $\mathrm{CD} 3{ }^{+} \mathrm{T}$ lymphocytes & $62(55-66)$ & 0.004 & 51 & & $54(33-59)$ & & $50(43-65)$ & $49(36-41)$ & $50(33-65)$ \\
\hline CD19 + B lymphocytes & $19(\underbrace{14-23)}$ & 0.004 & $13(10-18)$ & & $13(10-18)$ & & $12(9-19)$ & $11(9-18)$ & $12(9-15)$ \\
\hline $\begin{array}{l}\mathrm{CD} 3-/ \mathrm{CD} 16^{+}, \mathrm{CD} 56^{+} \\
\text {Natural killer cells }\end{array}$ & $18(13-24)$ & & $18(9-23)$ & & $20(9-24)$ & & $14(6-17)$ & $23(9-27)$ & $15(8-23)$ \\
\hline $\begin{array}{l}\text { CD4 + helper/ } \\
\text { inducer } \\
\text { T lymphocytes }\end{array}$ & $41(34-50)$ & & $34(28-44)$ & & $33(23-44)$ & & $35(30-46)$ & $33(29-42)$ & $35(23-46)$ \\
\hline $\begin{array}{l}\text { CD8 + suppressor/ } \\
\text { cytotoxic } \\
\text { T lymphocytes }\end{array}$ & $31(26-36)$ & & $28(25-35)$ & & $28(25-39)$ & & $27(19-31)$ & $28(25-41)$ & $27(19-31)$ \\
\hline $\begin{array}{l}\mathrm{CD} 4^{+}: \mathrm{CD}^{+} \\
\text {Ratio }\end{array}$ & $1.4(1.1-1.8)$ & & $1.2(0.9-1.5)$ & & $1.2(0.8-1.3)$ & & $1.3(1.1-2.1)$ & $1.1(0.8-1.2)$ & $1.3(1.1-2.1)$ \\
\hline $\begin{array}{l}\text { CD3 } \div \text { HLA-DR }+ \\
\text { Activated } \\
\text { T lymphocytes }\end{array}$ & $1.0(1.0-1.0)$ & & $1.0(0.0-1.0)$ & & $1.0(0.0-1.0)$ & & $1.0(0.0-1.0)$ & $0.5(0.0-1.0)$ & $1.0(0.0-1.0)$ \\
\hline
\end{tabular}

Ten microlitres of each antibody-combination was added to $50 \mu \mathrm{l}$ of whole blood, gently vortexed and incubated at room temperature for $20 \mathrm{~min}$ in the dark. FACS brand lysing solution $(1 \mathrm{ml} ; 1: 10)$ was added, vortexed again and incubated for exactly $10 \mathrm{~min}$ in the dark. After centrifugation at $250 \mathrm{~g}$ for $5 \mathrm{~min}$ at room temperature, the pellet was resuspended in $2 \mathrm{ml}$ phosphate buffered saline. After repeated vortexing and centrifugation, the pellet was resuspended in $500 \mu \mathrm{l}$ phosphate buffered saline and analysed within $24 \mathrm{~h}$ by using a FACScan flow cytometer. A minimum of 10000 total events was acquired to establish an analysis gate that included at least $95 \%$ of the lymphocytes and was contaminated by no more than $5 \%$ of the monocytes in the sample. A minimum of 2000 lymphocyte events was acquired from each tube. Immunophenotyping results were then obtained with SimulSET software automatically (all from Becton Dickinson Immunocytometry Systems, San Jose, Calif., USA). The sum of percentages of $T$ cells, B cells, and natural killer (NK) cells was used as an internal process control, by verifying that $\% \mathrm{~T}+\% \mathrm{~B}+\% \mathrm{NK}$ approximates $100 \% \pm 5 \%$.

\section{Antibody-assays}

(Anti-) $G A D$-antibodies ( $G A D$-ab). An immunoprecipitation assay with crude cytosolic extracts of Wistar rat brains was used to determine (anti-)GAD-antibodies as described previously $[18,19]$. Sera were regarded as positive if the GAD activity in immunoprecipitates was above $45 \%$ (mean +4 SD) of the activity in 81 non-diabetic control sera.

Insulin-autoantibodies (IAA). Sera were tested for IAA as previously described $[20,21]$ with a competitive fluid phase radio- binding assay and expressed in $\mathrm{nU} / \mathrm{ml}$ of insulin precipitated. The cutoff for insulin autoantibodies in cord blood was calculated from determinations in normal neonates of healthy mothers $(n=29$; mean $\pm \mathrm{SD}: 87 \pm 63 \mathrm{nU} / \mathrm{ml})$ and defined as positive above $213 \mathrm{nU} / \mathrm{ml}$ (mean $+2 \mathrm{SD})$. For children from 1 year to adulthood, $49 \mathrm{nU} / \mathrm{ml}$ (mean $+4 \mathrm{SD}$ ) as upper limit of normal was utilized [6].

Islet cell antibodies (ICA). Sections of blood group 0 cryofixed human pancreas were used for screening sera with peroxidase conjugated protein A. Results were expressed in Juvenile Diabetes Foundation Units (JDF-U) with a detection limit of $\geq 20$ JDF-U [22]. HbA $_{1}$ was measured by affinity chromatography (Testkit Boehringer Mannheim GmbH, Mannheim, Germany).

\section{Statistical analysis}

Significant differences between age groups were calculated by using a Mann-Whitney U test (non-paired Wilcoxon test; SPSS Inc., Chicago, Ill., USA). Differences were considered significant if $p$ was less than 0.05 . Distributions were asymmetric for most of the lymphocyte subsets. Hence, the median and interquartile ranges were used as quantitative descriptors of lymphocyte cell population distributions.

\section{Results}

Lymphocyte subsets in cord blood. Total lymphocytes and lymphocyte subsets were evaluated in cord blood from neonates from both diabetic and healthy moth- 
Table 3. Lymphocyte subsets (absolute counts and percentages) in children of diabetic mothers from birth to adulthood

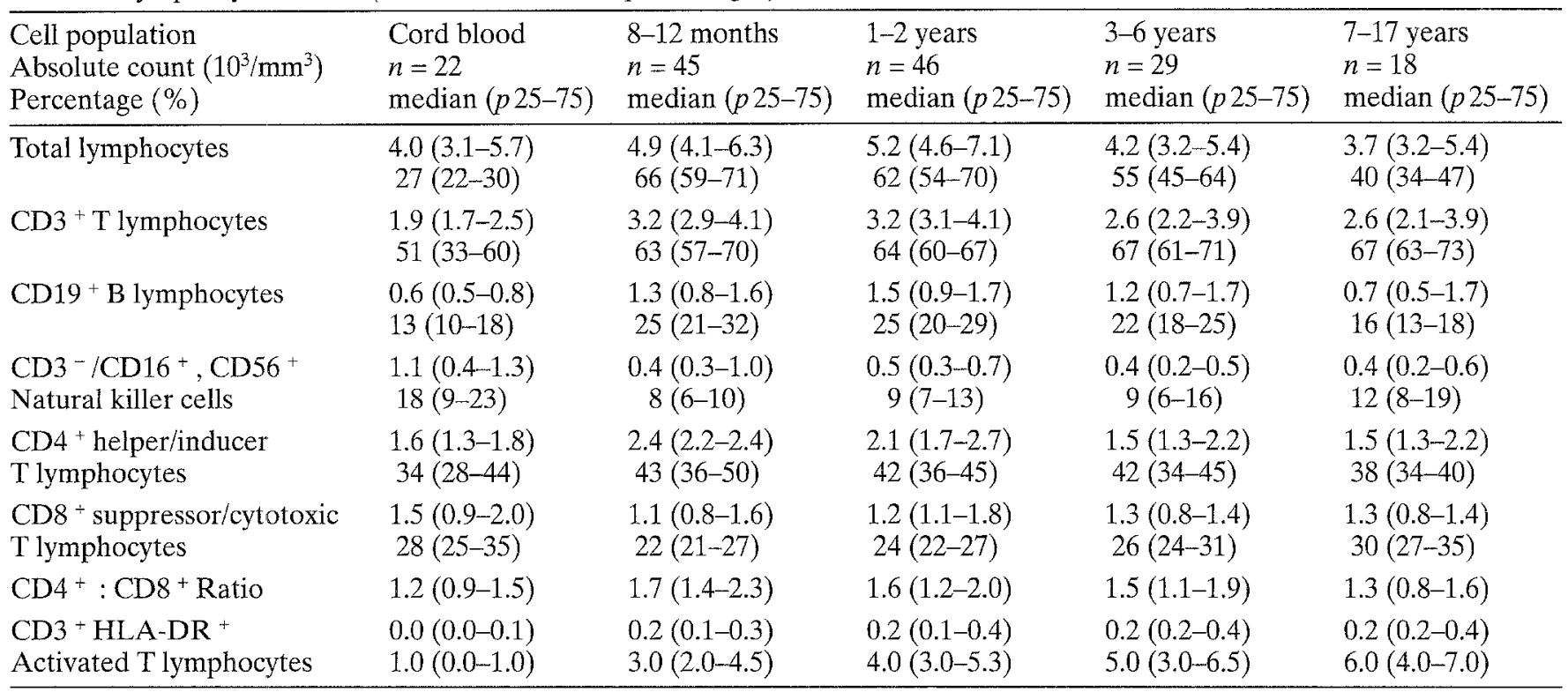

ers. A significant decrease of percentages of total lymphocytes ( $27 \%$ vs $30 \% ; p=0.044)$, including T lymphocytes (51\% vs $62 \% ; p=0.004)$ and B lymphocytes $(13 \%$ vs $19 \% ; p=0.004)$ was observed (Table 2). By subdividing children of diabetic mothers into neonates of gestational diabetic or of IDDM mothers, offspring of mothers with IDDM accounted for the significant differences in Tlymphocytes $(p=0.006)$, and B lymphocytes $(p=0.008)$, whereas neonates of mothers with gestational diabetes showed significant changes in total lymphocytes $(p=0.041$; Table 2). Neither maternal age, mean $\mathrm{HbA}_{1}$ during pregnancy, diabetes duration nor neonatal birth weight could explain these differences (correlation coefficient for $\mathrm{HbA}_{1}$ and total lymphocytes: $r=0.146$, T cells: $r=0.111$, B cells: $r=0.264$; $\mathrm{HbA}_{1}<$ median vs $\mathrm{HbA}_{1} \geq$ median $[=6.9 \%$ ] for total lymphocytes: $p=0.522$, for T cells: $p=0.567$, for B cells: $p=0.460$; correlation coefficient for diabetes duration and total lymphocytes: $r=0.226$, T cells: $r=0.304$, B cells: $\quad r=0.286$; diabetes duration $<$ median vs diabetes duration $\geq$ median $[=8.5$ years $]$ for total lymphocytes: $p=0.351$, for T cells: $p=0.663$, for B cells: $p=0.860$ ).

Age-related development of lymphocyte subsets. The results of our cross-sectional study in children of diabetic mothers at different ages are shown in Table 3 (absolute numbers and percentages of lymphocyte subsets). Compared to a reference population of paediatric subjects (Fig.1 A-H, left, median and 25.75.percentile), percentages of total lymphocytes were markedly higher in children of diabetic mothers at the age of 8-12 months and 1-6 years and were above the 75 th centile in $73 \%$ and $67 \%$ of the cases, respectively (Fig. $1 \mathrm{~A}$ ). In addition, percentages of activated $T$ cells were reduced at the age of
8-12 months, $1-6$ years and $7-17$ years and below the 25 th centile in $62 \%, 77 \%$ and $89 \%$ of the cases, respectively. No differences, however, were observed between children of mothers with IDDM and children of mothers with gestational diabetes throughout all age groups, regarding absolute numbers and percentages of all lymphocyte subpopulations (for percentages: Fig. $1 \mathrm{~A}-\mathrm{H}$, left, median and 25.75. percentile).

Lymphocytes in antibody-positive children of diabetic mothers. In all children of diabetic mothers, the influence of antibody-positivity on lymphocyte distributions was determined (Fig. $1 \mathrm{~A}-\mathrm{H}$, right: antibodypositive children vs antibody-negative children). At birth, 8 of 22 children of diabetic mothers were $\mathrm{I}(\mathrm{A}) \mathrm{A}^{+}$with titres of $261-1225 \mathrm{nU} / \mathrm{ml}, 4$ of 22 were $\mathrm{ICA}^{+}$and 3 of 22 had GAD-antibodies between 127 and $416 \%$. Neonates with at least one detectable antibody $(n=10)$ showed no differences in their lymphocyte subsets to neonates without antibodies $(n=12)$ except for a slightly higher absolute count of total lymphocytes $(p=0.046)$. Persisting antibodies which had developed at different ages were found in 7 of 93 children aged 1-17 years (Table 4) [19] and are considered to be at high risk for the development of IDDM. No significant alterations compared to antibody-negative low-risk children were observed in any of the tested lymphocyte subsets as demonstrated in Fig. 1 A-H (right). One of these children developed overt IDDM after 5 months.

Lymphocytes in children born prior to the onset of maternal diabetes. Twelve children (two children aged $1-6$ years and 10 children aged $7-17$ years) had healthy mothers at birth, who later on developed either IDDM or gestational diabetes $(n=6$, respective- 

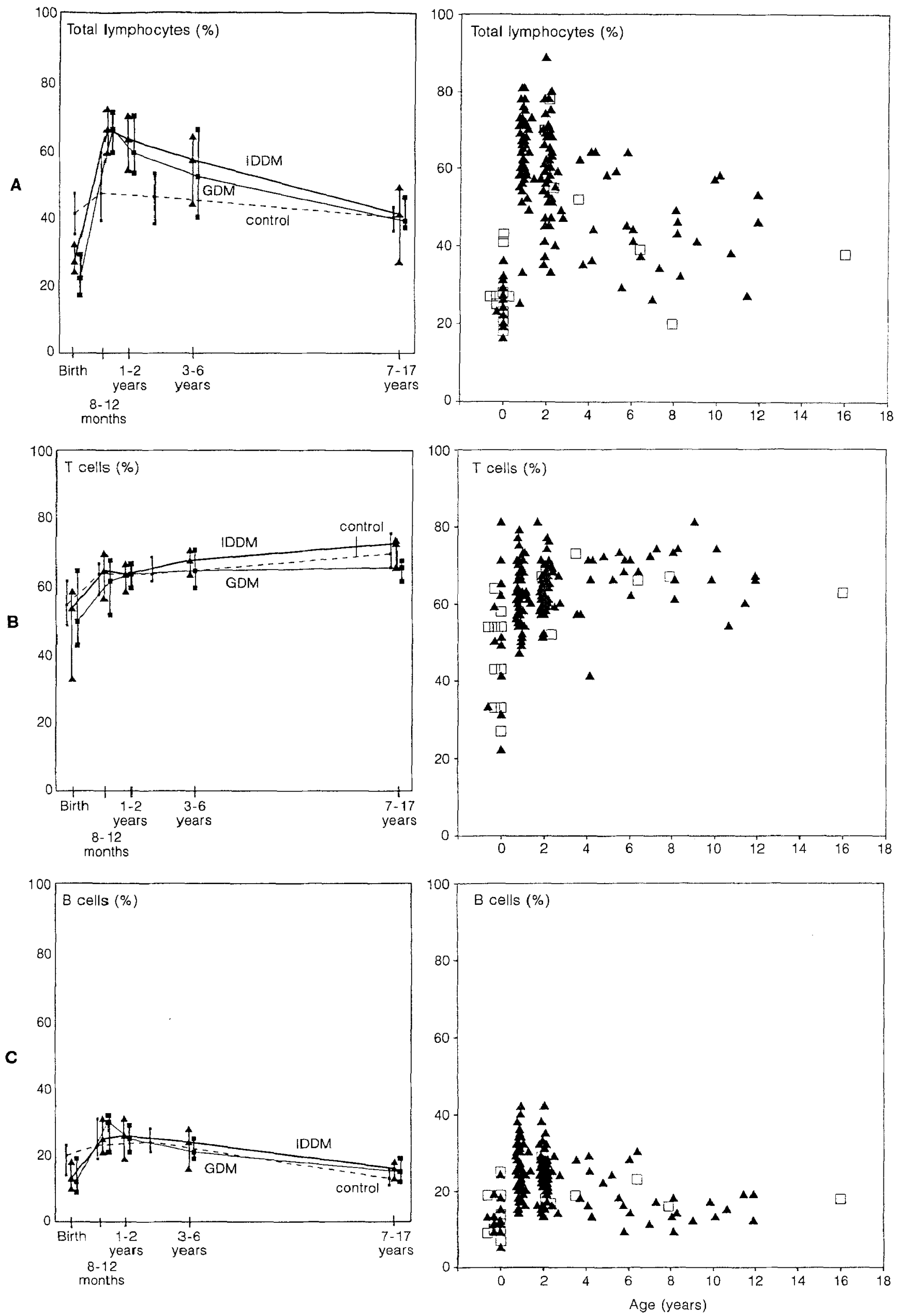

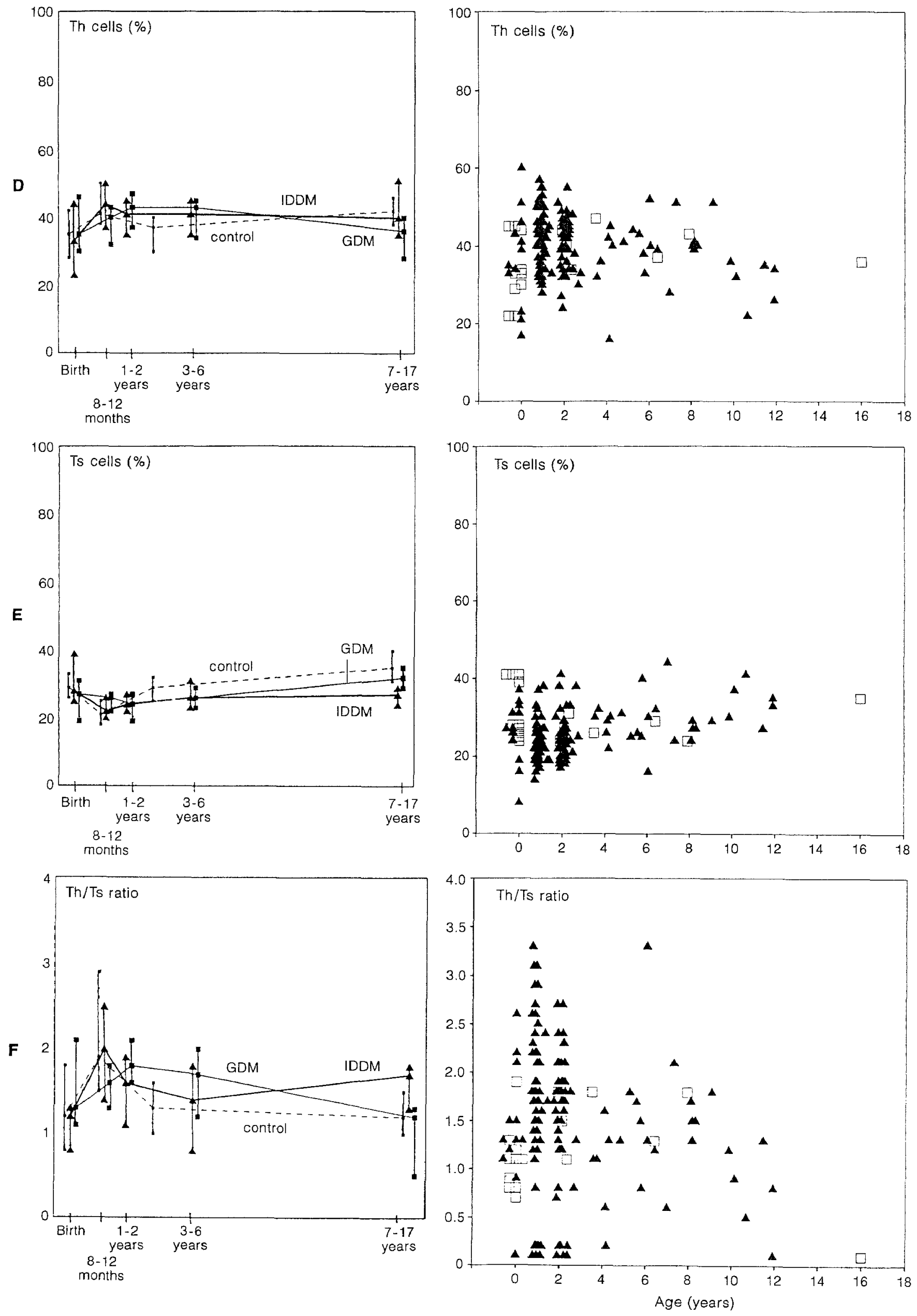

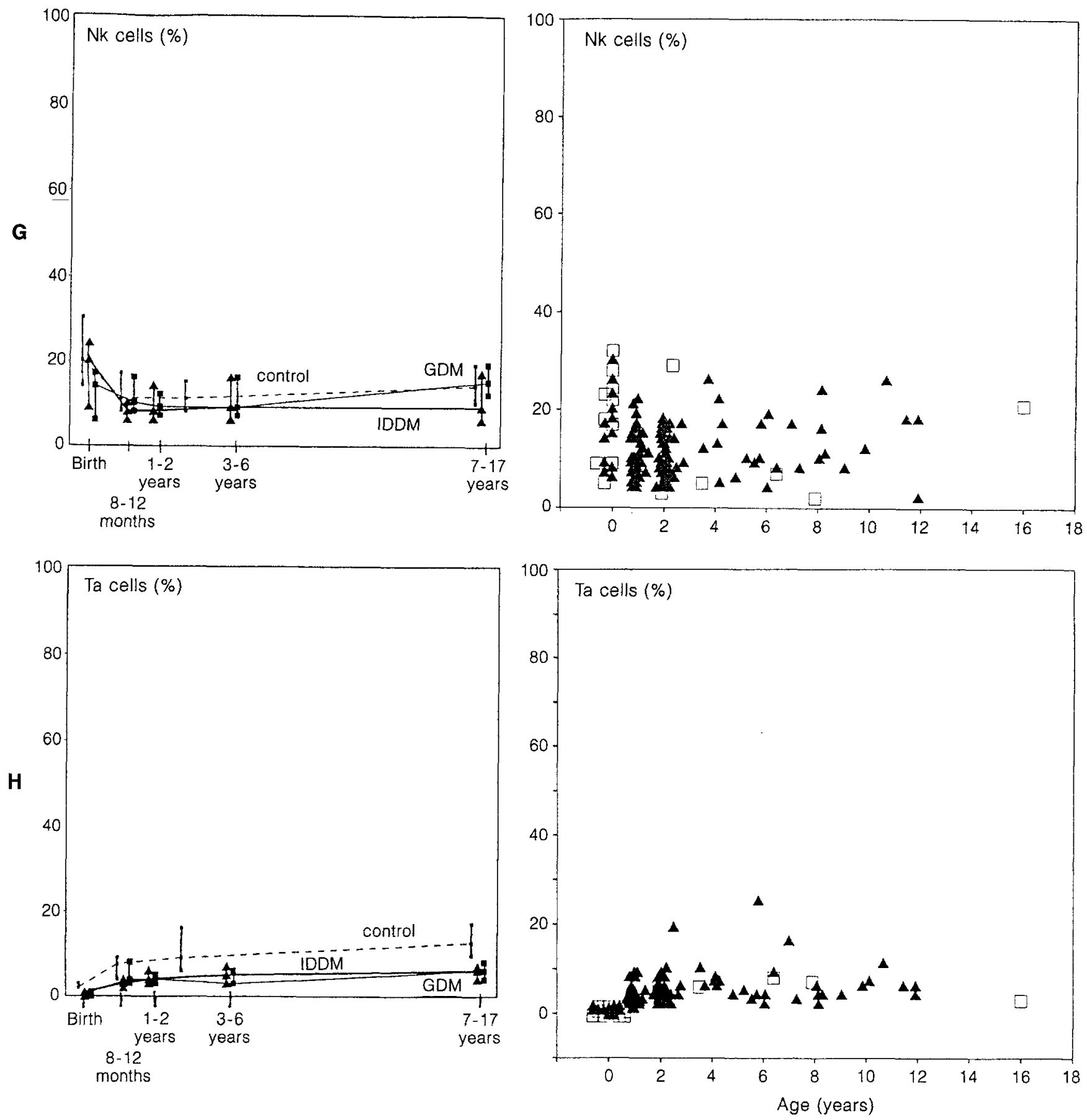

Fig. 1. (A-H) Percentages (median and 25.-75.centiles) of total lymphocytes (A) and subsets (B-H) from birth to adulthood. Left column: Comparison between offspring of mothers with IDDM (solid lines; closed triangles) and of mothers with gestational diabetes (thin line; closed squares). Dashed lines represent the median (and centiles: small dots) of a non-diabetic reference population. Right column: Comparison between antibody-negative (closed triangles) and antibody-positive (open squares) children of diabetic mothers $\square \mathrm{ab}+$; $\Delta \mathrm{ab}-$

ly) during their next pregnancy. No significant difference was observed between offspring of mothers with either IDDM or gestational diabetes and offspring born prior to the development of maternal diabetes in this small cohort.

\section{Discussion}

In the present study we were able to demonstrate differences in the distribution of lymphocyte subsets between offspring of diabetic and of normal mothers, indicating an existing influence of the maternal diabetic environment on the development of the fetal 
Table 4. Characterization of antibody-positive children

\begin{tabular}{|c|c|c|c|c|c|c|}
\hline No. & Sex & $\begin{array}{l}\text { Age } \\
\text { (years) }\end{array}$ & $\begin{array}{l}\text { Diabetes } \\
\text { in mother }\end{array}$ & $\begin{array}{l}\text { ICA } \\
\text { (JDF-U) }\end{array}$ & $\begin{array}{l}\text { IAA } \\
(\mathrm{nU} / \mathrm{ml})\end{array}$ & $\begin{array}{l}\text { GAD-ab } \\
(\%)\end{array}$ \\
\hline 1 & female & 2 & IDDM & 0 & 96 & 1 \\
\hline 2 & female & 2 & IDDM & 0 & 1174 & 7 \\
\hline 3 & male & 2 & GDM-A & 20 & 182 & 57 \\
\hline $4^{\mathrm{a}}$ & female & 4 & IDDM & 160 & 1278 & 90 \\
\hline 5 & female & 7 & later-GDM ${ }^{\mathrm{b}}$ & 0 & 109 & 20 \\
\hline 6 & female & 8 & later-IDDM ${ }^{b}$ & 0 & 34 & 193 \\
\hline 7 & female & 16 & IDDM & 0 & 150 & 0 \\
\hline
\end{tabular}

a Development of overt IDDM 5 months later; ${ }^{b}$ later-GDM or later-IDDM: onset of gestational diabetes or IDDM in the mother after the first pregnancy.

Upper limit of normal: ICA $<20 \mathrm{JDF}-\mathrm{U}$; IAA $49 \mathrm{nU} / \mathrm{ml}$; GAD-ab $45 \%$

immune system. In cord blood, percentages of total lymphocytes, Tlymphocytes and B lymphocytes were significantly reduced in children of diabetic mothers compared with children of healthy mothers. This reduction was mainly seen in cord blood of neonates of mothers with IDDM and to a lesser extent in neonates of mothers with gestational diabetes (Table 2). In addition, thoughout our cross-sectional study from birth up to the age of 17 years a marked increase in percentages of total lymphocytes (at the age of 8 months to 6 years) and a notable reduction in percentages of activated T cells (at the age of 8 months to 17 years) have been observed in children of diabetic mothers compared to a paediatric reference population (Fig. $1 \mathrm{~A}, \mathrm{H}$, left). The reference range was derived from a group of children, hospitalized in the UK and Belgium for minor trauma and surgical procedures. We are aware, that this population may not be totally representative for Germany and differences in coulter counter, FACSscan, and observer may influence the significance of our results. Nevertheless there was a general concordance in percentages of lymphocyte subsets between our population and the reference population, except for total lymphocytes and activated $T$ cells. We therefore suggest that this indicates true divergence.

No characteristic differences were detected between offspring of mothers with IDDM and gestational diabetes (Fig. 1). It is unclear why offspring of mothers with gestational diabetes in part exhibit similar abnormalities in the first years of life than offspring of mothers with IDDM. Gestational diabetes consists of a heterogenous group of women with an increased risk for non-insulin-dependent or insulindependent diabetes later in life. In our population, $67.4 \%$ of gestational diabetic mothers had either normal weight and/or were positive for beta-cell antibodies and two gave birth to children who developed persisting ICA later in life (Table 4). This indicates that a section of our patients including their offspring are more at risk of developing IDDM [23]. Consequently, this may imply that the observed chan- ges in children of mothers with gestational diabetes paralleled the changes in children of mothers with IDDM, since they were due to interactions with the maternal autoimmune disease. This is supported by the fact that no association was found between alterations of lymphocyte subsets and clinical variables such as diabetes duration or $\mathrm{HbA}_{1}$, respectively, and most of our diabetic mothers exhibited $\mathrm{HbA}_{1}$ levels within the normal range during pregnancy (mean $\mathrm{HbA}_{1}: 6.5 \%$, normal range $<8 \%$ ). Nevertheless, it is beyond doubt that blood glucose levels of diabetic subjects frequently exceed those of non-diabetic individuals. In addition, $32.6 \%$ of gestational diabetic women were overweight without any sign of autoimmunity and rather at increased risk for non-insulindependent diabetes. Therefore, it has to be considered that the unstable metabolic control of diabetic mothers itself substantially contributes to the observed alterations of lymphocyte counts in their offspring.

In cord blood, $45.5 \%$ of neonates of diabetic mothers were found to have at least one antibody, most likely transmitted through the placenta from the diabetic mother [6]. Antibody-positivity in cord blood is a transient phenomenon in the majority of children of mothers with IDDM, and it is still to be evaluated whether and in which way this has some bearing on the occurrence of IDDM in the offspring. By analysing differences in cord blood of antibody-positive and antibody-negative neonates, only minor changes were observed in the absolute counts of total lymphocytes $(p=0.046)$, suggesting that placentally-acquired antibodies have no major influences on the maturation of the cellular immune system (Table 2).

Considering the reported low risk of IDDM in children who have been exposed to the IDDM of their mothers in utero [24], or in offspring of diabetic mothers compared to those of diabetic fathers or to siblings [2], one could speculate that alterations of lymphocyte subsets in these offspring might reflect protective mechanisms of the fetal immune system in response to the mother's autoimmune disease [4]. If so, one would expect that children with a higher risk for IDDM, as for example children with positive anti-islet antibodies or children born before the onset of the mother' disease [5], lack these "protective" abnormalities. Therefore, lymphocyte subsets of children with persisting antibodies $(n=7)$ and of children born prior to their mother's diabetes onset $(n=12)$ were independently analysed. However, no consistent and significant abnormalities were observed in these two small cohorts of children compared to "low-risk" antibody-negative offspring or to age-matched children born after the manifestation of the disease, respectively (Fig. 1 right).

A number of studies have described alterations in lymphocyte subpopulations in newly-diagnosed IDDM subjects, but conflicting reports concerning 
the nature of these changes have been published [ 8 14]. In antibody-positive first-degree relatives, Faustman et al. $[11,16]$ reported an elevation in suppressor/inducer cells $\left(\mathrm{T} 4{ }^{+} 2 \mathrm{H} 4{ }^{+}\right)$, whereas helper/inducer cells $\left(\mathrm{T} 4{ }^{+} 4 \mathrm{~B} 4^{+}\right)$were reciprocally depressed. In contrast, Johnston and co-workers [10] studied pairs of identical twins discordant for IDDM and demonstrated a reduction of $\mathrm{CD} 8{ }^{+}$suppressor/cytotoxic cells in both the affected diabetic and the nondiabetic twin, suggesting that this reduction appears to be genetically determined. One very recent report investigated lymphocyte subsets in siblings and parents of IDDM subjects, and described a reduced number of $\mathrm{CD} 4{ }^{+}$helper cell counts in siblings and a decreased percentage and number of $\mathrm{CD}^{+}{ }^{+} \mathrm{T}$ lymphocytes in their parents compared with age-matched controls [14]. In addition, siblings and parents had significantly increased levels of activated CD4 ${ }^{+}$ T lymphocytes.

To date, we are not aware of any publication of lymphocyte subsets in children of mothers with IDDM or with other autoimmune diseases, except for one report from Di Mario and colleagues [25], who examined lymphocyte subsets in pregnant women and their neonates, including unreported numbers of women with non-insulin-dependent, insulindependent, and gestational diabetes. In contrast to our findings, no differences have been described between neonates of diabetic and of normal mothers in this population. The heterogeneity of the type of diabetes, and the use of a different immunofluorescence technique might account for these differences.

In conclusion, we suggest that the observed alterations of lymphocyte subsets in children of diabetic mothers symbolize a cellular immune reaction to the particular maternal environment, characterized by both an abnormal metabolic state and persisting autoimmunity in the affected mother. This may be responsible for the reported low risk of these offspring of developing IDDM later in life.

Acknowledgements. We gratefully acknowledge A.Lenz, M. Hummel and all nurses of the delivery room (Department of Gynaecology, City Hospital Schwabing) for collecting blood samples, and J.Vordemann and U. Mollenhauer for help in sample preparation and lymphocyte subset analysis. We are indebted to H.J.Vogt for the possibility of using the Becton Dickinson Cytometer and R. Heimerl for providing technical assistance (Technical University, Biederstein, Munich). This work was supported by a grant from the 'Bundesministerium für Forschung und Technologie' (01KD89030) and the 'Braun-Stiftung' (Zi 31/07/92). A.-G. Ziegler was supported by the 'Deutsche Forschungsgemeinschaft' (Heisenberg $\mathrm{Zi} 310: 6-1$ ), and U.Roll by the 'Studienstiftung des Deutschen Volkes'. This study was part of the dissertation of J. Scheeser, Ludwig-Maximilian-University, Munich.

\section{References}

1. Bonifacio E, Bottazzo GF (1991) Immunology of IDDM (type 1 diabetes): entering the '90s. In: Alberti KGMM, Krall LP (eds) Diabetes annual 6. Elsevier, Amsterdam pp 20-47

2. Warram JH, Krolewski AS, Gottlieb MS, Kahn CR (1984) Differences in risk of insulin-dependent diabetes in offspring of diabetic mothers and diabetic fathers. N Engl J Med 311: 149-152

3. Tillil H, Kobberling J (1987) Age-corrected empirical genetic risk estimates for first-degree relatives of IDDM patients. Diabetes 36: 93-99

4. Warram JH, Krolewski AS, Kahn CR (1988) Determinants of IDDM and perinatal mortality in children of diabetic mothers. Diabetes 37: 1328-1334

5. Warram JH, Martin BC, Krolewski AS (1991) Risk of IDDM in children of diabetic mothers decreases with increasing maternal age at pregnancy. Diabetes 40: 16791684

6. Ziegler A-G, Hillebrand B, Rabl Wet al. (1993) On the appearance of islet associated autoimmunity in offspring of diabetic mothers: a prospective study from birth. Diabetologia 36: 402-408

7. Bottazzo GF, Dean BM, McNally JM, Mackay EH, Swift PG, Gamble DR (1985) In situ characterization of autoimmune phenomena and expression of HLA molecules in the pancreas in diabetes mellitus. N Engl J Med 313: 353-360

8. Galluzzo A, Giordano C, Rubino G, Bompiani GD (1984) Immunoregulatory T-lymphocyte subset deficiency in newly diagnosed type 1 (insulin-dependent) diabetes mellitus. Diabetologia 26: 426-430

9. Ziegler AG, Standl E, Lander T, Nerl C, Rieber EP, Mehnert $H$ (1987) Cell-mediated autoimmunity at onset of insulin-dependent diabetes mellitus (IDDM). Klin Wochenschr 65: 546-550

10. Johnston C, Alviggi L, Millward BA, Leslie RDG, Pyke DA, Vergani S (1988) Alterations in T-lymphocyte subpopulations in type 1 diabetes. Exploration of genetic influence in identical twins. Diabetes 37: 1484-1488

11. Faustman D, Eisenbarth G, Daley J, Breitmeyer J (1989) Abnormal T-lymphocyte subsets in type 1 diabetes. Diabetes 38: 1462-1468

12. Peakman M, Hussain MJ, Millward BA, Leslie RDG, Vergani D (1990) Effect of initiation of insulin therapy on Tlymphocyte activation in type 1 diabetes. Diabet Med 7: $327-330$

13. Buschard K, Damsbo P, Röpke C (1990) Activated CD4 + and CD8 + T-lymphocytes in newly diagnosed type 1 diabetes: a prospective study. Diabet Med 7: 132-136

14. Peakman M, Warnock T, Vats A et al. (1994) Lymphocyte subset abnormalities, autoantibodies and their relationship with HLA DR types in children with type 1 (insulin-dependent) diabetes and their first degree relatives. Diabetologia 37: $155-165$

15. Hitchcock CL, Riley WJ, Alamo A, Pyka R, Maclaren NK (1986) Lymphocyte subsets and activation in prediabetes. Diabetes 35: 1416-1422

16. Faustman D, Schoenfeld D, Ziegler R (1991) T-lymphocyte changes linked to autoantibodies. Associations of insulin autoantibodies with CD4 + CD45R + lymphocyte subpopulation in prediabetic subjects. Diabetes 40: 590-596

17. Erkeller-Yuksel F, Deneys V, Yuksel B et al. (1992) Age-related changes in human blood lymphocyte subpopulations. J Pediatr 129: 216-222

18. Christie MR, Brown TJ, Cassidy D (1992) Binding of antibodies in sera from type 1 (insulin-dependent) diabetic pa- 
tients to glutamate decarboxylase from rat tissues: evidence for antigenic and non-antigenic forms of the enzyme. Diabetologia 35: 380-384

19. Roll U, Christie MR, Standl E, Ziegler A-G (1994) Associations of anti-GAD antibodies with islet cell antibodies and insulin autoantibodies in first-degree relatives of type 1 diabetic patients. Diabetes 43: 154-160

20. Ziegler AG, Ziegler R, Vardi P, Jackson RA, Soeldner JS, Eisenbarth GS (1989) Lifetable analysis of progression to diabetes of anti-insulin autoantibody positive relatives of individuals with type 1 diabetes. Diabetes 38: 1320-1325

21. Greenbaum CJ, Wilkin TJ, Palmer JP (1992) Fifth international serum exchange workshop for insulin autoantibody (IAA) standardization. Diabetologia 35: 798-800
22. Greenbaum CJ, Palmer JP, Nagataki S et al. (1992) Improved sensitivity of ICA assays in the fourth international immunology of diabetes serum exchange workshop. Diabetes $41: 1570-1574$

23. Ziegler AG, Hillebrand B, Standl E (1993) Inselzellantikörper und Insulin-Autoantikörper bei Schwangeren mit Gestationsdiabetes. Eine postpartale Verlaufsbeobachtung. Diabetes und Stoffwechsel 2: 51-55

24. Buschard K, Kühl C, Molsted-Petersen L, Lund E, Palmer J, Bottazzo GF (1989) Investigations in children who were in utero at onset of insulin-dependent diabetes in their mothers. Lancet I: 811-814

25. Di Mario U, Dotta F, Gargiulo P et al. (1987) Immunology in diabetic pregnancy: activated $\mathrm{T}$ cells in diabetic mothers and neonates. Diabetologia 30: 66-71 